\title{
Research on the Application of Traditional architectural symbols of the Dwellings Decoration in Southern Hubei
}

\author{
Dong $\mathrm{Li}^{1}$, a Sun Chuan ${ }^{2,}$ b \\ ${ }^{1}$ Wuhan University of Science and Technology, Wuhan, Hubei 430065, China \\ ${ }^{2}$ Hubei University of Education, Wuhan, Hubei 430205, China \\ a,bsuper_dongli@sina.com
}

Keywords: traditional architectural symbols, traditional dwellings in southern Hubei, decorations, modeling

\begin{abstract}
This paper takes the area of south of Hubei province as the main research field, making analysis and research on the architectural space and traditional culture of traditional dwellings in this area; through the construction of modern traditional dwellings' decoration and design in the south of Hubei province and the modeling analysis of the architectural decoration symbols of traditional dwellings in southern Hubei, this paper makes effective understanding and application analysis on the decorating space features of traditional dwellings in this area and applies it in the point-line-surface, so as to make this kind of decorative symbols inheriting original culture create a kind of attractive architectural landscape atmosphere.
\end{abstract}

\section{Introduction}

During recent years, to satisfy people's physical and psychological demand, traveling industry is developed around the country; meanwhile, the government makes emphasis on investing and building the scenic spots with features, and the rebuilding of traditional dwellings with cultural and regional features becomes rather important in the process of pushing the traveling industry forward $^{[1,2]}$.

Against the background of economic globalization, in front of the strong trend of foreign culture, traditional dwellings with regional and national cultural confront with the emergency of gradual disappearance. Therefore, this paper makes research on the architectural semiotic features of traditional dwellings in southern Hubei, putting forward the induction and classified analysis of the architectural features of traditional dwellings in southern Hubei with the theory of semiotics; after making deconstruction of the symbols in traditional dwellings in southern Hubei, this paper concludes the principles and methods of applying traditional dwellings symbols southern Hubei in the creative designs of regional architecture, providing certain theoretical evidence and referential values for the inheritance and development of traditional dwellings in southern Hubei.

\section{Decoration design of modern traditional dwellings in southern Hubei}

In the south of Hubei province, the climate is humid and hot with a lot of rain; the terrain is mainly hills; the production mode is mainly mountain farming; under the guidance of traditional agriculture, handicraft industries of paper making, and tea making are development. As for the geographic position of the southern Hubei, it is to Wuhan in the north, connecting Hunan province in the south, next to the north of Jiangxi province in the east, and against to Jingxiang area in the west; it has modern decoration design of traditional dwellings in southern Hubei.

It is in the convergence zone of three provinces of Hubei, Jiangxi and Hunan. Therefore, there are certain similarities in climate, geography and other objective environment with surrounding provinces, so is in culture; mainly speaking, its culture is in the same structure with Han culture in central plains. Meanwhile, around the south of Hubei province, there are mainly subcultures with regional characteristics around the southern Hubei, such as Huizhou culture, Ganjiang culture, 
Huxiang culture, and Xiajiang culture. The regional culture of the southern Hubei is at the edge of the four subcultures, instead of integrating into one of them; however, these four subcultures penetrate into each other, the effect of which is exerted to this area; as a result, its culture is at the edge, having particularity in identity and identity in particularity.

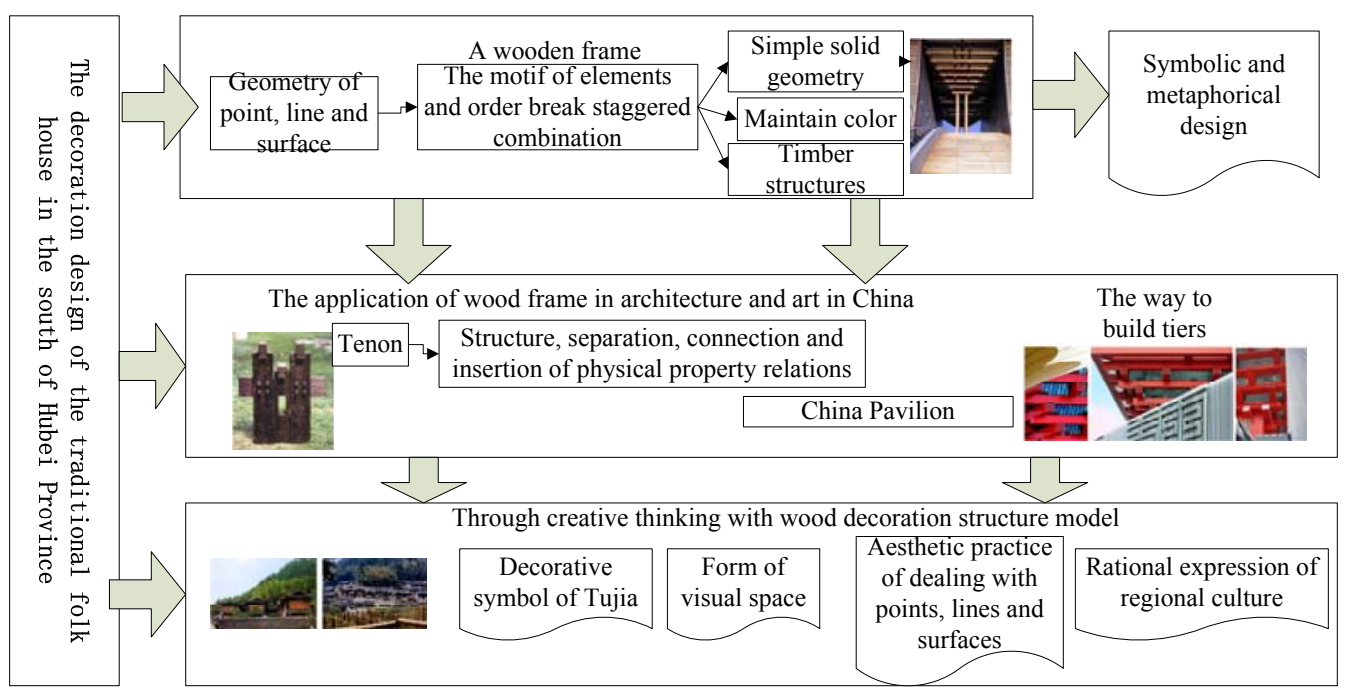

Figure 1:Decoration design figure of modern traditional dwellings in the south of Hubei province

As is shown in Figure 1, the traditional dwellings in the south of Hubei province is formed and developed in the farming society; in the atmosphere of strong patriarchal system of the central plains, the courtyard buildings in southern Hubei are also equipped with the basic characteristics of the courtyard in the central plains; however, under the constraints of objective natural conditions and local humanistic spirits, strong regional adaptation is shown, such as courtyard with small architectural volume, lifted courtyard space leaning against mountains, as well as houses along town streets born under the effect of local agriculture and handicraft, which can satisfy trade and residential demands. In the process of design, many decoration symbols on in the south of Hubei province is accumulated; therefore, at the time of designing regional signs and wharfs, thoughts are recombined and the forms of tenon-and-mortise work and wooden structure are applied in scenery.

\section{Analysis on the modeling characteristics of the decoration symbols in traditional dwellings of the southern Hubei}

As is shown in Figure 2 and 3 , Clans and village layout often limited objective geographical conditions, which resulted in a ring and the change of ribbon trend. In the houses around the pattern and if encountered insurmountable obstacles, it will become exhibit cyclic patterns when encountered insurmountable obstacles around the pattern of the houses, such as mountains Gaoqiao Town Rao village. The village is located in the center of several mountain, but with the Family expanded reproduction, the new housing will be only to develop to the direction of the mountain,in that case, which the Housing can be progressively from the center to the edge with the mountain lift high and a ring around the form under the influence of the mountain slope. Zonal distribution form is mainly for saving farmland considerations.In order to occupy as little arable land, when the house one side is mountainous, settlement will occur zonal distribution.The picture is a town of Tongshan County Zicheng a group settlement so that the direction of development of housing only along the foot of the contour line and be free up more ground for cultivation. This settlement layout approach is gradual, and led to the living space settlements gradually expand due to the increase in population. 

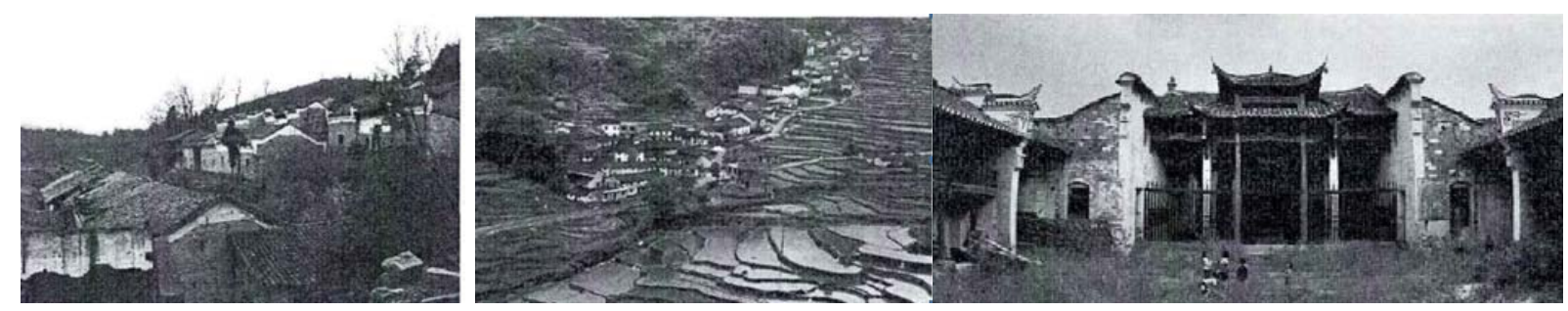

Figure 2: Rao Settlement mountains ring with zonal distribution Figure 3: Wen Wang Zhen settlement with zonal distribution ring Figure 4: Tongshan County Hall Tan

When people decorated with the theme of the story, the modeling process often carried by bold exaggeration and very dramatic tension in order to make people immersive. People can not pursue proportion, but a small head and big body artistic can be operated to intended to highlight the dynamic look and character. The story scenes are not rigidly adhere to the size perspective, in order to balance the overall picture of the primary principle and the characters and background complement (Figure 5). This picture shows that make the whole structure of the actual situation and white picture by bas-relief, engraved and carved yin and yang lines. In order to produce stunning artistic effect, we can use patchwork, with full vivid distinctive variety of figures.
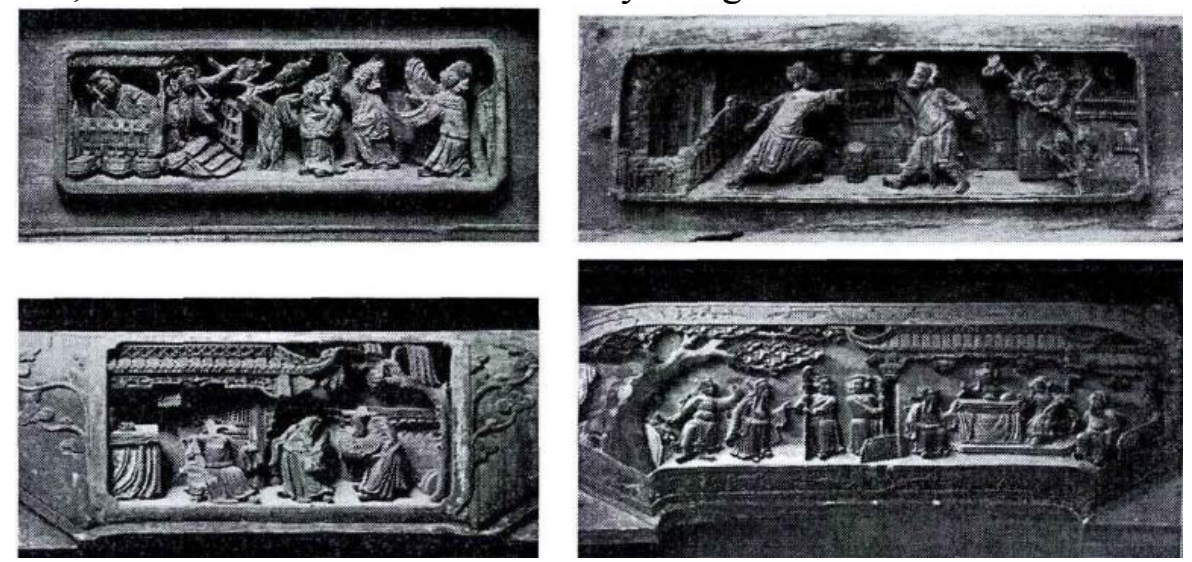

Figure 5: Folk carvings show scenes of people

As is shown in Table 1, these are the modeling methods of decoration symbols. There are several basic forms for constructive modes, such as “一” shape, “L” shape, “凹” shape, “回” shape, and so on; through the combination of these basic forms, large courtyard gradation takes form and settlement gradation begins to take shape.

Table 1:Modeling laws for decoration symbols

\begin{tabular}{|c|c|c|}
\hline $\begin{array}{l}\text { Settlement } \\
\text { gradation }\end{array}$ & Structure & Characteristics \\
\hline "—" shape & $\begin{array}{l}\text { The main house and the stilted } \\
\text { part form "一" shape. }\end{array}$ & $\begin{array}{l}\text { The form of stilted building is very special and } \\
\text { rarely seen; the main house is not stilted, but one } \\
\text { end of the main house is stilted. }\end{array}$ \\
\hline "L" shape & $\begin{array}{l}\text { The building plane forms the "L" } \\
\text { shape, comprise one main house, } \\
\text { two or three floors, which are } \\
\text { built on stilts according to } \\
\text { terrain. }\end{array}$ & $\begin{array}{l}\text { Stilted buildings are mostly houses opened in two } \\
\text { sides with smaller width than the main house. }\end{array}$ \\
\hline “凹” shape & $\begin{array}{l}\text { There are stilted houses on the } \\
\text { left and right of main house. }\end{array}$ & $\begin{array}{l}\text { The enclosed feeling is stronger than "L" shape } \\
\text { building, but the spatial intention is divergent, } \\
\text { tending to contain outer and inner space. }\end{array}$ \\
\hline “回” shape & $\begin{array}{l}\text { The building forms the residence } \\
\text { of "courtyard". }\end{array}$ & $\begin{array}{l}\text { Connect the upper part of the two stilted houses at } \\
\text { both ends of the main house, to form a courtyard; } \\
\text { different from the courtyard of Han nationality, it } \\
\text { takes the form of turrent courtyard. }\end{array}$ \\
\hline
\end{tabular}




\section{Reliability analysis of decorative symbols of traditional dwellings in southern Hubei and their application}

This paper aims to study the application relationship of architectural traditional symbols in traditional dwellings decoration in southern Hubei; the model to describe the relationship between observational variables and latent variables is measurement model, and the model to describe the relationship between latent variables is structural model. The matrix equation of the two parts in SEM is as following:

1) Measurement model:

$$
\begin{aligned}
& x=\wedge_{x} \xi+\delta \\
& y=\wedge_{y} \eta+\varepsilon
\end{aligned}
$$

$\mathrm{x}$ is the vector quantity composed of exogenous index; $\mathrm{y}$ is the vector quantity composed of endogenous index; $\wedge_{x}$ is the relationship between exogenous index and exogenous latent variable, which is the factor loading matrix of exogenous index in exogenous latent variable; $\wedge_{y}$ is the relationship between endogenous index and endogenous latent variable, which is the factor loading matrix of endogenous index in endogenous latent variable.

2) Structural model:

As for the relationship among latent variables, the structural equation is often written as:

$$
\eta=B \eta+\gamma \xi+\zeta
$$

Regression analysis is used to conduct tests on the model hypothesis; this study adopts the mostly commonly used reliability coefficient, Cronbach's $\alpha$ coefficient, to signify reliability. The criterion of reliability coefficient in this study is shown in Table 1.

Table 2: Criterion of reliability coefficient

\begin{tabular}{llll}
\hline & $\begin{array}{l}\text { Questionnaire } \\
\text { coefficient }\end{array}$ & reliability & $\begin{array}{l}\text { Univariate reliability } \\
\text { coefficient }\end{array}$ \\
\hline $\mathrm{a}$ & 0.7 & 0.5 \\
\hline
\end{tabular}

Through calculation, this study discovers that the composite reliability (CR) of all the research variables are over 0.8 , higher than the critical value of 0.5 ; therefore, it can be regarded that the results of the questionnaire is reliable. It indicates that the measurement scale in this study has high internal

\begin{tabular}{|c|c|c|c|}
\hline Symbol factor & $\begin{array}{l}\text { Item number } \\
\text { measure }\end{array}$ & in Cronbach's $\alpha$ & $\begin{array}{l}\text { Composite reliability } \\
\text { (CR) }\end{array}$ \\
\hline Index & 5 & 0.881 & 0.881 \\
\hline Icon & 6 & 0.880 & 0.883 \\
\hline Symbol & 3 & 0.805 & 0.822 \\
\hline $\begin{array}{l}\text { Total architectural } \\
\text { symbols }\end{array}$ & 4 & 0.909 & 0.943 \\
\hline
\end{tabular}
consistency and can reach the reliable level.

Table 3:Results of reliability analysis on the influence of traditional architectural symbols

Results show that the standardized loading coefficients of each observable variables in corresponding architectural symbol factors are all above $0.5,0.56-0.92$; the $t$ value of factor loading is 12.16-21.67, passing $t$ test and oustanding on the level of $\mathrm{p}<0.001$. Meanwhile, all the AVE is higher than 0.5. AVE is to calculates the average variation explanatory power of relevant variable of measure item number; the higher is AVE value, the higher the reliability of this variable. The criterion is that AVE is higher than 0.5. In this study, all the latent variables' AVE is higher than 0.5. Therefore, this study has rather high convergent validity on the measurement of latent variables. 


\section{Analysis and application of decoration spatial features in traditional dwellings of southern Hubei}

Courtyard is the most typical composition form of unit space in the traditional dwellings of southern Hubei; large-scale residence is composed of multiple groups of courtyards in horizontal or vertical directions, to constitute "large houses" with momentum and scale. The vertical connection of courtyards is called as "yard"; crossing the first courtyard, you enters the second, and the rest can be done in the same manner; large-scale residence has three to five yards or more. The horizontal chaining of courtyards is called as "line", which means "a line of several open rooms"; the typical residents is usually "three open rooms" or "five open rooms", which can also be called as "three in a line" or "five in a line". Taking a residence with three open rooms horizontally and two in a line in vertical direction as example, local people mostly use such expressions as "two yards in a line and three open rooms in each yard" or "two yards with three open rooms in each" to describe the scale of this residential unit. Commonly, the front side of residence is the horizontal side facing streets, with the entrance in the center of the front side; therefore, the number of rooms is usually odd number, with the axis in the middle open room, which is closely related to Chinese classical architecture axial asymmetry principle in the graphic composition, making the whole building have the beauty of balance. In the southern area of Hubei, there is also particular case of combination type, which means in large-scale residence, courtyard and common yard combine; this kind of combination is more common in the adjacent area of Hunan and Hubei provinces, but rarely seen in southern Hubei. The composition forms which are similar to courtyard houses have two courtyards or several courtyards, or small yards surrounded by low walls in front of gates, to take shape of spacious forecourt. For example, Wang MingFan's residence, located in Dalu Town, Tongshan County, is a large residence composed of compound courtyard. (Figure 6)

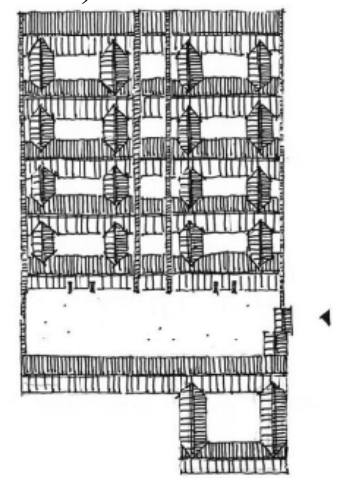

Figure 6: Plane graph of Wang MingFan's residence

The site selection of traditional dwellings in southern Hubei and even settlement; the locations are mostly at the slight slope of the foot of mountains and distributed in straps or clusters. This kind of village forms located along mountains make houses create favorable conditions of ventilation and lighting. Leaning against mountains can keep out winter cold current brought by monsoon climates; however, in summer, the whole village can enjoy natural wind blown from the south, which creates good ventilation environment and seems to be quite applicable in the muggy and humid climate in southern Hubei. Compared with large-scale residence in the plain area, houses in mountains have smaller volumes and are more compact; even large buildings can be broken up into many small-scale units, the relationship in functions of which can be realized through yards, winding corridors, and so on (Table 4). Therefore, the overall arrangement is more flexible and changeable; generally speaking, besides the core part of residence, other auxiliary rooms can change according to the needs of functions or changes of terrain. 
Table 4: Adaptation of buildings of small volume to the environment

\begin{tabular}{|l|l|l|}
\hline Legend & \\
\hline $\begin{array}{l}\text { Descripti } \\
\text { on }\end{array}$ & $\begin{array}{l}\text { Buildings of large volume should be } \\
\text { dug in mountains to a large degree at } \\
\text { the time of construction. }\end{array}$ & $\begin{array}{l}\text { Buildings of small volume should conform to the } \\
\text { trend of mountain land, which can reduce the } \\
\text { influence to the base to the minimum. }\end{array}$ \\
\hline
\end{tabular}

The transformation on the mountain land in house construction is local; gentle and mild land should be selected first; the original characteristics of land base should be kept to the most in the mountain land; manners of artificial digging and backfill which cost time and labor and destroy natural environment should be rarely adopted. On one hand, it is limited by construction techniques and economic conditions; on the other hand, it can be taken as the final results of mutual selection between human beings and the nature. As for the courtyard buildings constructed in slight slopes, the scales of yards are small and the shape is irregular as the architectural distribution needs certain extension space; the elevation difference of front and back yards mainly depends on the step transition in courtyard. Brick is the building materials applied in traditional dwellings in southern Hubei . Black brinks are burnt in high temperature from clay bricks, boiled in hot water and got dried, which have essential differences from bricks made of soil; they have rather great elevation in such performances of abrasion resistance and fire-resistance. Although black bricks have common characteristics with stone material in mechanical property and are suitable for bearing pressure, black bricks are more convenient in collection and processing of raw materials. As brick-making is developed manually by local people, size and standard are different in different regions; different black bricks also have different means of making, which are important embodiment of traditional construction techniques. (Table 5)

Table 5: Common categories commonly seen in southern Hubei

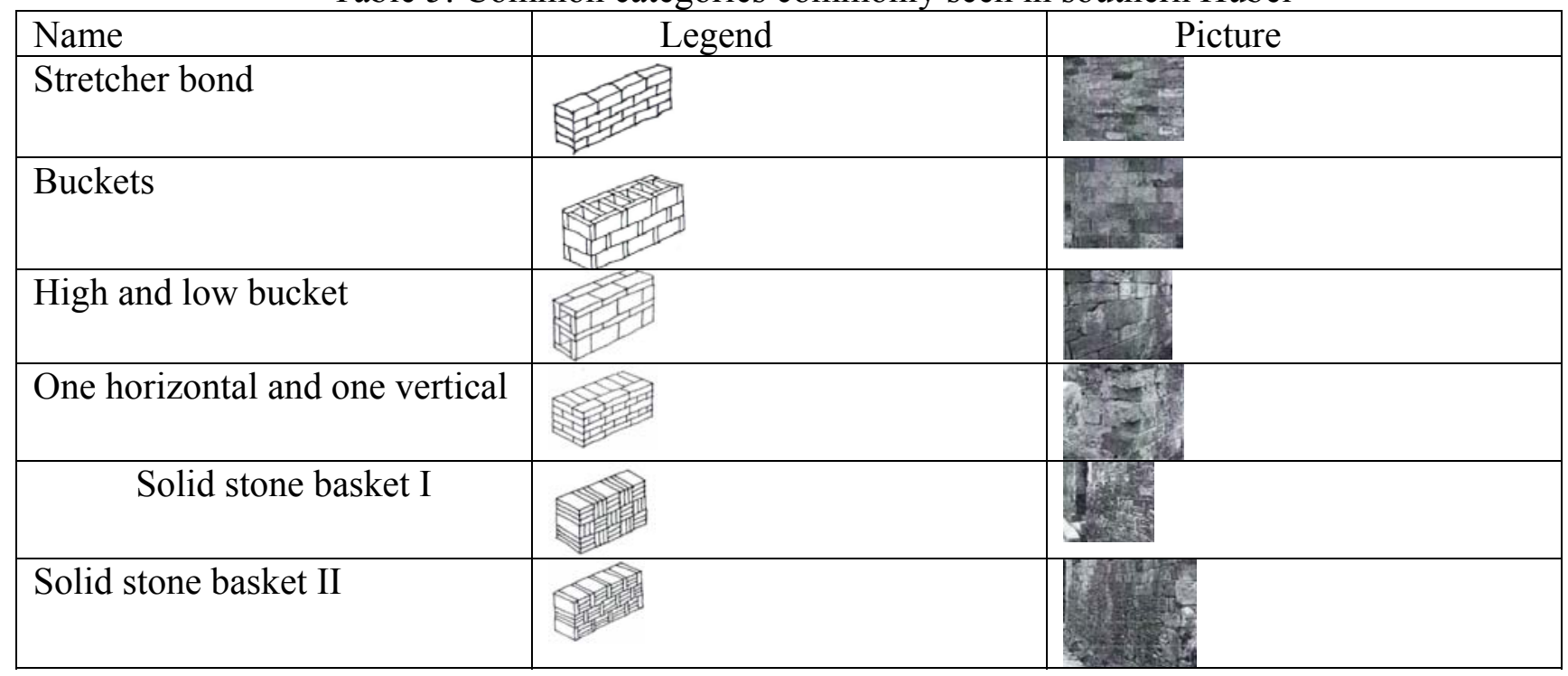

The regeneration of architectural symbols should lay emphasis on the presentation of spatial sequence; the spatial distribution is distant in somewhere and thick in other place, with plenty of layers, combining virtuality and reality, which can create beauty of vacancy. In conclusion, Chinese traditional architectural spatial organization methods, both the symmetry, ratio, and rhythm, and the affectionate materials and sizes, applications in colors, and even the creation techniques of its overall spatial order and pattern metaphors in the indoor space, deserve the study and reference of present architectural decoration design. As is shown in Figure 9, the influence of spatial shapes, size and spatial separation and relations on the psychology of human beings is emphasized; it is necessary to 
learn the uniqueness of models from traditional components and to create architectural decoration components with traditional cultural connotation.
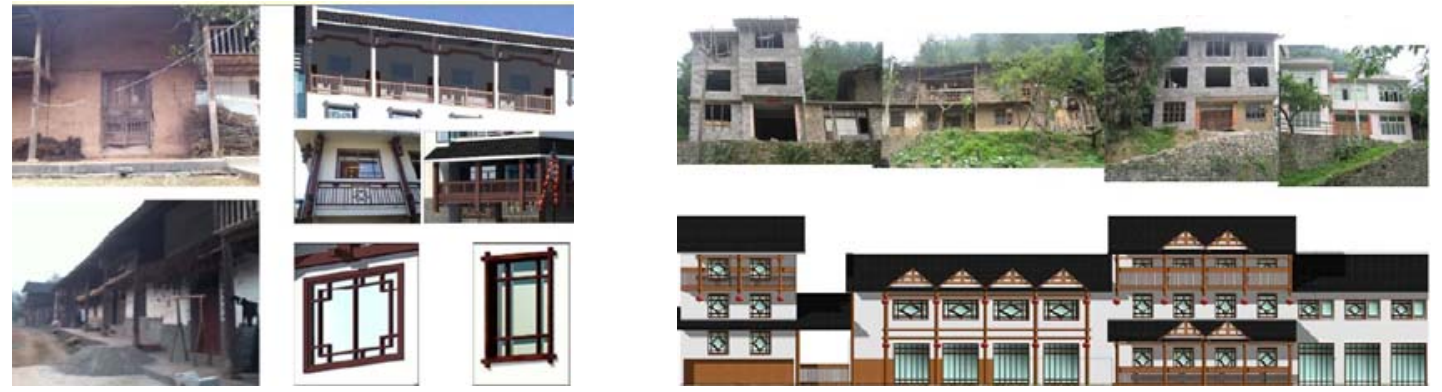

Figure 7:Comparison between traditional stilted building component and modern design stilted building component Figure 8:Comparison between before and after reformation

At the time of facade reconstruction design of buildings, it is intentional to continue the local dominant hue, extracting local traditional color composition formation including color proportional allocation, application position, and so on to take it as the basis of color constitution in the modern building's facade reconstruction design, which can help modern buildings gain national features. As is shown in Figure 9, the double eaves of building front facade are applied in the gable wall of building; the displacement provides people with new visual experience. There is another design method of application after changing traditional element entity shapes, such as simplification, warping, overlapping, breakage, abstraction, and so on. This method can create strong effect and has strong sense of symbol. The repeated application of symbols after change has emphasis effect on theme and makes people associate.

\section{Conclusions:}

The harmonious relationships between human beings and buildings, and between human beings and nature, are integrated in the creation of Chinese traditional dwellings; from architectural site to house layout, from structure to material, and from decoration means to decoration parts, the means in harmony with natural environment are adopted, and relatively comfortable, green, healthy, low energy consumption or even no energy consumption interior and outdoor environment is built under the circumstance of now auxiliary high technology to improvement environment, which has decisive advantages over the the ecology of modern residence. Traditional dwellings, as a compound ecological system, is a special but integrative system for human beings' production, living and residence, with unique spatial and ecological features; in the process of taking form, it follows a kind of similar design process, which comes from the regional conditions of traditional dwellings and originates from the experience of human beings in the long-term life and practice.

\section{References}

[1] Zhao Zhongding. Xiangxi family stilted building component study field. Central South University of Forestry and Technology, 2014,pp12-13.

[2] Zhang Yunyun. Study on Xiangxi traditional folk house building symbols and its modern expression. Hunan University, 2010, PP 82-85.

[3] Li Changhong, Shu Ping, Zhang Min. Discussion on the inheritance and development of stilt style architecture in folk houses. Journal of Tianjin Urban Construction Institute, 2007, pp15-17.

[4] Lu Yuanding. Decoration and fitment art of Chinese folk house. Beijing: China Architecture \& Building Press, 2004,pp 98-101.

[5] Zhang Weiran. Study on the history, culture and geography of Hubei province. Wuhan: Hubei educational culture press, 2000.pp10-11.

[6] Zhang Zhang. Design and structure of civil architecture. Beijing: Science press, 2002,pp81. 
[7] Lu Yuanding. Exploration of ways to study civil folk house from the laws of traditional folk house building formation. Architect, 2005, pp032.

[8] Li Baihao. Exploration on the functions, form, and culture of vernacular architecture in Hubei province. Central China Architecture, 2007,pp13-15.

[9] Jiang Lan. Study on the climate adaptability of vernacular architecture in southeastern Hubei province. Wuhan: Huazhong University of Science and Technology, 2005.

[10] Guo Yacheng. Transformation and development of settlement in village and small towns in southeastern Hubei province ---- taking villages in Yangxin, Tongshan, and Chongyang regions as example. Wuhan: Huazhong University of Science and Technology, 2007. 